\title{
Gallbladder Hydrops Due to Viral Hepatitis A Infection: A Case Report
}

\author{
Mitra Aldaghi ${ }^{1, *} ;$ Mahmoud Haghighat ${ }^{1} ;$ Seyed Mohsen Dehghani ${ }^{1}$ \\ ${ }^{1}$ Department of Pediatric Gastroenterology, Namazi Hospital, Shiraz University of Medical Sciences, Shiraz, IR Iran \\ *Corresponding author: Mitra Aldaghi, Department of Pediatric Gastroenterology, Namazi Hospital, Shiraz University of Medical Sciences, Shiraz, IR Iran. Tel/Fax: +98-7116242534, \\ E-mail:Aldaghi@sums.ac.ir
}

Received: January 14, 2014; Revised: August 8, 2014; Accepted: August 30, 2014

\begin{abstract}
Introduction: Acute Hepatitis A Virus (HAV)infection is common in the developing countries among children, but hydrops of gallbladder due to hepatitis A infection is an uncommon presentation.

Case Presentation: A five-year-old boy was admitted in Namazi Hospital, Shiraz, Iran due to jaundice and severe abdominal pain for 10 days. Physical examination revealed a mass in the right upper quadrant with severe tenderness. Liver function tests were abnormal while other laboratory data such as blood urea nitrogen, serum creatinine, sodium, and potassium were within the normal range. Blood and urine cultures were negative. Abdominal ultrasonography showed that the gallbladder was very much distended and its fundus was near the iliac crest. Hydrops of the gallbladder was diagnosed. HAV IgM titer was high. After five days, without any specific treatment, his symptoms improved and he was discharged with good condition.

Conclusions: Acute acalculous gallbladder disease is a rare complication of HAV infection which should be suspected in any child with right upper quadrant abdominal pain, tenderness, and mass which can lead to surgical emergency in rare conditions.
\end{abstract}

Keywords:Gallbladder; Children; Hepatitis A

\section{Introduction}

Acute acalculous gallbladder disease is classified as either hydrops or acalculous cholecystitis. The distinction between these two conditions may be difficult. These diseases may present with a spectrum of symptoms ranging from transient gallbladder distention with spontaneous resolution to acute acalculous cholecystitis (AAC) with necrosis of the gallbladder wall (1). Acute hydrops is defined by marked gallbladder distention in the absence of calculi, bacterial infection, or congenital gallbladder anomaly. The absence of a significant inflammatory component and its typically benign prognosis are the features that distinguish hydrops from acalculous cholecystitis (1). One of the conditions related to gallbladder hydrops is viral hepatitis and gallbladder hydrops due to viral hepatitis A is rarely reported in children (2). Here is the presentation of infection in a five-year-old boy with hydrops of gallbladder due to Hepatitis A Virus (HAV), which is rarely reported in the pediatric age group.

\section{Case Presentation}

A five-year-old boy was admitted in Namazi Hospital, Shiraz, Iran with severe abdominal pain, jaundice and low grade fever. Similar symptoms were reported in his family about 30 days ago. He had abdominal pain and vomiting from 20 days before admission; his jaundice worsened and developed from 10 days ago. At the time of admission he was very sick with fever and yellowish discoloration of skin and sclera. He was very irritable due to abdominal pain. In the physical examination he had normal growth parameters and his vital signs were as follows: temperature: $38^{\circ} \mathrm{C}$, pulse rate: $100 / \mathrm{min}$, respiratory rate: $30 / \mathrm{min}$ and blood pressure: $100 / 60 \mathrm{mmHg}$. In the abdominal examination, a large mass was palpated in the right upper quadrant (RUQ) with severe tenderness. Initial laboratory investigations showed elevated liver enzymes: AST: $516 \mathrm{U} / \mathrm{L}$, ALT: $722 \mathrm{U} / \mathrm{L}$, alkaline phosphatase: $1930 \mathrm{U} / \mathrm{L}$, total bilirubin: $5.3 \mathrm{mg} / \mathrm{dL}$, direct bilirubin: 3.9 mg/dL, total protein: $7.7 \mathrm{~g} / \mathrm{dL}$, albumin: $3.8 \mathrm{~g} / \mathrm{dL}, \mathrm{WBC}$ : 8000/mm³ 3 Hb: $11.9 \mathrm{~g} / \mathrm{dL}$, platelet: $426000 / \mathrm{mm}^{3}$, CPR: 6 $\mathrm{mg} / \mathrm{dL}, \mathrm{ESR}: 40 \mathrm{~mm} / \mathrm{h}$. Coagulation studies revealed PT: 13 sec, PTT: 34 sec and INR: 1. Serum amylase, blood sugar and serum sodium, potassium, BUN and creatinine were within normal range. Venous blood gas analysis revealed: $\mathrm{pH}: 7.5, \mathrm{HCO}_{3}: 30$, and $\mathrm{PCO}_{2}$ :37.9. Blood and urine cultures were negative. Serology of viral hepatitis was positive for HAV IgM, and other viral markers were negative. Serology titers for typhoid and brucellosis were negative. Abdominal ultrasonography showed normal size and echogenicity of the liver, with significantly distended gallbladder ( span $130 \times 50 \mathrm{~mm}$ ) with the fundus of gallbladder near iliac crest. The thickness of gallbladder wall was normal and no stone was detected. The hydrops of gallbladder was confirmed by ultrasonography (Figure 1).

Due to fever and toxic condition, he received antibiotic ceftizoxim and metronidazole. After the third day of admission, his fever and blood culture became negative

Copyright (C) 2015, Ahvaz Jundishapur University of Medical Sciences. This is an open-access article distributed under the terms of the Creative Commons Attribution-NonCommercial 4.0 International License (http://creativecommons.org/licenses/by-nc/4.0/) which permits copy and redistribute the material just in noncommercial usages, provided the original work is properly cited. 
and antibiotics were stopped. Surgical intervention was not required in the patient. After five days, general condition and abdominal pain of and jaundice improved and he was discharged with close follow up.

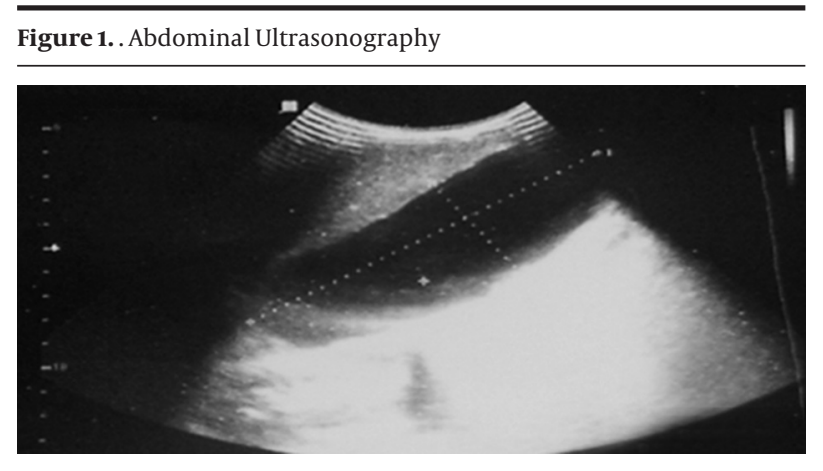

Abdominal ultrasonography showed normal size and echogenicity of the liver, with significantly distended gallbladder (span $130 \times 50 \mathrm{~mm}$ ); fundus of gallbladder was near iliac crest. The thickness of gallbladder wall was normal and no stone was detected. The hydrops of gallbladder was confirmed.

\section{Discussion}

Hepatitis A Viral infection is a wide spread infection throughout the world. In the developing countries, hepatitis A viral infection is common during childhood. In these countries, $92 \%$ to $100 \%$ of the 18 -year-old people have serologic evidence of past infection (1). Infants and toddlers are more likely to be asymptomatic (anicteric hepatitis), whereas the majority of adults will develop clinically evident hepatitis (1). One of every 12 young children develops jaundice, and children are more likely than adults (60\% vs. $20 \%$ ) to have diarrhea, often leading to the mistaken diagnosis of infectious gastroenteritis (1). Gallbladder hydrops due to hepatitis A viral infection is uncommon and is exceptionally described in the literature (2-4).

Abdominal pain, vomiting, and RUQ mass in abdominal examination are the typical presentations of gallbladder hydrops. Kawasaki syndrome (5), mesenteric adenitis with pressure over cystic duct (5), streptococcal and staphylococcal infections with the associated toxin production (6), viral hepatitis, Henoch-Schoenlein purpura (7) and hypokalemia (8) had reported association with hydrops of gallbladder. Other etiologies include tumors, polyps or malignancy of the gallbladder, spontaneously resolved acute cholecystitis, congenital narrowing of the cystic duct, parasites such as ascaris (occasionally), prolonged parenteral nutrition, typhoid, leptospirosis, and appropriate response to ceftriaxone therapy (1). Although the etiology is unclear, invasion of the gallbladder and bile duct epithelial by hepatitis A viral infection and cell-mediated immunologic response are proposed in the pathogenesis of cholecystitis resulted from HAV infection (9).

Low grade fever, colicky abdominal pain, vomiting, right sub costal tenderness, and a palpable tender mass in RUQ are common (1). A mild, direct hyperbilirubinemia may also be present. If the infection left untreated, it can rapidly progress to gallbladder gangrene and perforation leading to peritonitis, sepsis, and shock. In uncomplicated acute cholecystitis, liver function tests are normal or there is only slightly liver enzyme elevation. Mild cholestatic abnormalities (increased bilirubin up to $4 \mathrm{mg} / \mathrm{dL}$ and elevated alkaline phosphatase) are common, probably indicating the mechanical obstruction of the cystic duct resulting from intrinsic inflammation of the biliary tract (10). The diagnosis of hydrops is generally made by abdominal ultrasonography demonstrating a markedly distended, echo-free gallbladder with normal wall thickness and a normal-caliber biliary tree. Serial ultrasonographic examination is useful to monitor the patient and detect the resolution (10).

Surgery should be reserved for the exceedingly rare complications of gallbladder perforation. Symptomatic abdominal pain may resolve after one or two days (11). The treatment of gallbladder hydrops varies depending on the clinical condition. Most cases are self-limited and size of the gallbladder may spontaneously become normal with treatment of the underlying disease within approximately two weeks (1). In conclusion, in the case of hepatitis A viral infection with severe abdominal pain and specially RUQ abdominal mass, hydrops of gallbladder should be kept in mind as a possible complication and abdominal ultrasonography should be done accordingly.

\section{Acknowledgements}

Authors acknowledged their gratitude to the parents of the child for their collaboration.

\section{Authors' Contributions}

Mahmoud Haghighat is responsible for literature search and manuscript editing; Seyed Mohsen Dehghani was the supervisor and followed the case; Mitra Aldaghi wrote the draft and collected data.

\section{References}

1. Rumley TO, Rodgers BM. Hydrops of the gallbladder in children. J Pediatr Surg. 1983;18(2):138-40.

2. Uysal G, Cengizlier R, Guven MA, Ozhan B. Hydrops of the Gallbladder associated with infection: A report Of Two Cases. Turk J Gastroenterol. 2000;11(1):84-7.

3. Suresh DR, Srikrishna R, Nanda SK, Annam V, Sunil K, Arjun B. Acalculous gallbladder distension in a young child due to HAV infection: Diagnostic dilemma. Indian J Clin Biochem. 2009;24(3):316-8.

4. Arroud M, Benmiloud S, Oudghiri B, Afifi MA, Hida M, Bouabdallah Y. Acute acalculous cholecystitis revealing hepatitis A virus infection in children. Saudi J Gastroenterol. 2009;15(4):277.

5. Friesen CA, Gamis AS, Riddell LD, Roberts CC, Jackson MA. Bilirubinuria: an early indicator of gallbladder hydrops associated with Kawasaki disease. J Pediatr Gastroenterol Nutr. 1989;8(3):3846.

6. Dickinson SJ, Corley G, Santulli TV. Acute cholecystitis as a sequel 
of scarlet fever. Am J Dis Child.1971:121(4):331-3.

7. McCrindle BW, Wood RA, Nussbaum AR. Henoch-Schonlein syndrome. Unusual manifestations with hydrops of the gallbladder. Clin Pediatr (Phila).1988;27(5):254-6.

8. Goren A, Drachman R, Hadas-Halperin I, Drukker A. Transient gall bladder dilatation associated with hypokalaemia in a patient with Bartter syndrome. Eur J Pediatr. 1989;149(2):88-9.

9. Portincasa P, Moschetta A, Di Ciaula A, Palmieri VO, Milella M, Pastore G, et al. Changes of gallbladder and gastric dynamics in patients with acute hepatitis A. Eur J Clin Invest. 2001;31(7):617-22.

10. Dalgıc N, Ince E, Ciftci E, Oncel S, Gunes M, Fitoz S, et al. Acute viral acalculous cholecystitis due to viral hepatitis A.J Ankara Univ Fac Med. 2005;58(2).
11. Ozaras R, Mert A, Yilmaz MH, Celik AD, Tabak F, Bilir M, et al. Acute viral cholecystitis due to hepatitis A virus infection. J Clin Gastroenterol. 2003;37(1):79-81. 